Talía. Revista de estudios teatrales

ISSN-e 2659-806X

\title{
Sometimiento o aniquilación del ser indigno: crueldad colectiva en Divinas palabras
}

\author{
Lucía Cotarelo Esteban*
}

Recibido: 19 de noviembre de 2019 / Aceptado: 6 de febrero de 2020

Resumen. En el cosmos preesperpéntico de Divinas palabras, un desfile grotesco e inauténtico de personajes organizados en torno al heterotópico mundo de la farándula y al doctrinal mundo rural, hacen del engendro Laureano y la adúltera MariGaila sus víctimas. En un sentido trascendido de la crueldad -del modo en que Artaud o Nietzsche lo concibieran-, la lógica moral se ceba con estos representantes de la degradación humana, considerados indignos en tanto que disidentes de los marcos categoriales de normalidad y de decencia. La represión sufrida por estos títeres del fanatismo, y el asco producido por la figura animalizada, desembocan en la violencia más guiñolesca que aflora ante la necesidad de someter a la femme fatale, de aniquilar al monstruo.

Palabras clave: Divinas palabras, Valle-Inclán, crueldad, Mari-Gaila, Laureano.

\section{[en] Subjection or annihilation of the unworthy being: collective cruelty on Divinas Palabras}

Abstract. The monstrous Laureano and the adulterous Mari-Gaila become victims of the grotesque and inauthentic group of characters which create the preesperpentic Divinas palabras world -built around an heterotopic set of show business and the dogmatic rural environment-. Applying a trascended perspective of cruelty as both Artaud and Nietzsche did, the moral logic attack these human degradation representatives: as unworthy beings, outsiders of the categorial framework of normality and decency, they deserve the society sentence. Both the self-repression of this puppet society and the rejection of the animalized human being lead in violence. The femme fatale needs to be subjected; the monster needs to be annihilated.

Keywords: Divinas palabras, Valle-Inclán, cruelty, Mari-Gaila, Laureano.

Cómo citar: Cotarelo Esteban, L. (2020). Sometimiento o aniquilación del ser indigno: crueldad colectiva en Divinas palabras, en Talía. Revista de estudios teatrales, 2, 83-89.

De creación inmediatamente anterior a Luces de bohemia, el universo de Divinas palabras (1920) alberga un diálogo triple: uno estético -entre simbolismo y expresionismo-, otro ontológico - entre dos mundos contrapuestos, el rural galaico y el de la farándula-, y otro genérico - entre las versiones relativizadas e irónicas de tragedia y comedia-. Su conjugación configura la cosmovisión carnavalesca de este antecedente tan próximo al esperpento valleinclanesco, que algunos críticos consideran ya acumulador de prácticamente todos sus elementos [Iglesias Feijoo 1991], y dota a la obra de un carácter esencialmente mixto. Subtitulada Tragicomedia de aldea $^{1}$, queda inscrita en la tradición grotesca ${ }^{2}$-de "trágica mojiganga" y "fantoches trágicos"-: distorsión de estéticas y géneros elaborada por y para satisfacer una desmitificación progresiva del ser humano que escondió su rostro bajo la máscara. Desde el Amphitruo de Plauto, señala Iglesias Feijoo [1991: 19], la infracción de las normas que supone la ideación de la tragicomedia, en la incongruente conjugación de elementos que la define, "era un explosivo que no merecía otra salida que la de inventarse un absurdo, una quimera, un monstruo cómico". Divinas palabras "encierra dentro de sí el trágico hálito de la muerte", sí, pero "la muerte ha

\footnotetext{
* Universidad Internacional de La Rioja.

Email: luciacotarelo@ucm.es

Valle-Inclán emplea hasta catorce denominaciones genéricas o modelos para sus obras, siendo esta la única tragicomedia, y la inmediatamente previa al primer esperpento así denominado, Luces de bohemia [Cabañas Vacas 1991: 16]

Según Pavis (1984) la entendió, como mezcla de géneros y estilos.
} 
dejado de ser heroica" [1991: 19]; encierra dentro de sí también una aparente batalla entre las fuerzas del bien y el mal, pero se trata de una "batalla maniquea irónica" entre dos fuerzas que, al fin, demuestran su semejanza [Crispin, 1988]. Entre los supuestos contrarios se produce el choque, y del enfrentamiento nacen el desconcierto y el cuestionamiento general, el derrumbamiento de las categorías artísticas y morales.

La inautenticidad de la cultura occidental obliga al ser humano, en su desconocerse, "a un constante fingir" que convierte a la sociedad en "una reunión de máscaras" [Jerez Farrán 1989:109-110]; farsa que se ve vencida por el desgarramiento de las pieles tejidas por el dogma y cosidas a los rostros, exhalando la carne viva un primer aliento de rebeldía. El esperpento exhibe el desdoblamiento de un mundo oficial resquebrajado: de forma desafiante y provocativa destapa la caja de Pandora a la que las instituciones, la moral social y la tradición relegan a la antinorma, la otra cara de la moneda. Junto a Valle-Inclán, otros como Artaud y Nietzsche fustigaron la sociedad falsa, pueril, irresponsable del mundo oficial. En este espacio distópico, exento de actitudes elevadas y saturado de valores puramente virtuales que no calan en el individuo, el aspecto físico adquiere un matiz ético al mostrar la fealdad que el dramaturgo-filósofo intuye como realidad metafísica interior del ser humano. Este es el modo pesimista en que críticos como Kayser entendieron la deformación corporal presente en las manifestaciones artísticas de lo grotesco, que deriva inevitablemente en la deshumanización: el artista contempla de forma cínica el mundo, a sus ojos tan solo un vacuo teatro de marionetas, ridículo y objeto de risa [Polák 2011:48]. Esta variante que Kayser distinguió como "grotesco satírico" se revela en la obra de Valle-Inclán, quien halla el modo de vencer esa inautenticidad en la toma de conciencia de lo absurdo de la realidad y la trascendencia de su condición trágica por medio de la burla [Cardona y Zahareas 1987:60-61]. Esta mirada satírica es la que Valle-Inclán adopta casi inevitablemente al ocuparse del mundo oficial, pues en su propia esencia está arraigado lo grotesco ${ }^{3}$.

Este mundo oficial de alienación está en Divinas palabras representado por una de las dualidades ontológicas mencionadas: el espacio rural galaico, una aldea poblada por títeres del dogma católico. El aspecto de sus infraestructuras, viejas y decrépitas, contribuye a la idea del desgastamiento de las estructuras del dominio; el empobrecimiento de sus habitantes, a la de la condensación moral en una serie cerrada y reducida de valores, totalmente ineficaz a la hora de acoger la heterogeneidad humana. Para acceder a estos entornos, Valle-Inclán emplea todavía un lenguaje preciosista en algunas de sus acotaciones que funde y deriva hacia otro propiamente esperpéntico. Se produce así una deformación que puede afectar de un modo bien paulatino, bien tremendamente súbito, a una bella naturaleza truncada por el desagradable plano social que entorpece el fluir armónico del entorno con su aspecto ridículo y repulsivo. En esta condición reside la correlación física grotesca de la degradación moral:

Prima mañana, rosadas luces, cantos de pájaros. En la copa de las higueras abren los brazos derrengados peleles y dos marranos gruñen sobre el dornajo ante la puerta aún cerrada de MARICA DEL REINO. La vieja, raída y pelona, saca la cabeza por el ventano, y con gritos espanta a las bestias (Divinas palabras, II, 9 $)^{4}$.

Así es advertida Marica del Reino en la plácida mañana, quien fuera descrita en primer lugar como una "vieja encorvada que da gritos con el rostro entre las manos" (I, 4). Como ella, otros integrantes de la aldea, o procedentes de ella, son descritos en clave colorista y simbólica como seres deshumanizados: Juana la Reina es una "figura triste y color tierra" (I, 1); Rosa la Tatula, un "garabato negruzco de una vieja encorvada" (III, 3), etc. Pero ante todo, son las figuras del poder civil y religioso las que resultan más afantochadas: los guardias civiles devienen "pareja de tricornios, negra y polvorienta", y es el Sacristán de la aldea quien percibe, como pilar esencial de este mundo milagrero, el efecto más funesto de la esperpentización. Continúa así la habitual caricaturización de la moral cristiana y sus representantes del clero presente en las obras valleinclanescas [Ena, 2006]. Se trata de "un viejo fúnebre, amarillo de cara y manos, barbas mal rapadas, sotana y roquete", con "cuatro pelos [...] ojos con estrabismo" (I, 1), que remite siempre al mortuorio color de los cirios y a la oscuridad -"La sombra del sacristán, larga y escueta" (II, 9); "negro en la angosta sotana" (III, 1)-: personaje integrado en su paradójico entorno, destinado al culto divino pero teñido siempre por las penumbras.

El mundo de la farándula, auténtico espacio desinhibido de ferias y romerías, de vidas ambulantes con el que la estática representación-relativa- de la oficialidad dialoga, está conformado, a diferencia del primero, por un elenco de personajes y realidades de una gran heterogeneidad: "mendigos y trajinantes de toda laya, negros segadores, amancebados criberos, mujeres ribereñas que venden encajes, alegres pícaros y amarillos enfermos" (II, 7), que emiten en este espacio atestado con olor a sardinas un barullo de coplas. La música y el baile, el alcohol y la taberna, el erotismo; la violación del decoro así como el desinterés por las falsas apariencias; lo escandaloso, lo grosero, las burlas; el ateísmo, y el satanismo incluso, encuentran su lugar en este espacio creado para la profanación de la norma. Vitalismo, rebeldía y espontaneidad lo definen. Representante de este mundo como contrapunto del Sacristán, Lucero -también llamado Séptimo o Compadre Miau, en constante alusión al Diablo- es un titiritero pícaro y burlesco, don Juan lascivo, ingenioso, blasfemo y republicano. A diferencia del resto de personajes del mundo de aldea, mirados desde arriba, Lucero es mirado de frente, quizás por su ocupación de marionetista, similar a la del dramaturgo. 
El mundo de la farándula se alza frente al rural dogmático como inversión, como distorsión y profanación de la norma sagrada. De este modo, Valle-Inclán construye en Divinas palabras su propia versión de un universo carnavalesco al provocar el encuentro entre realidades opuestas, del modo en que Bajtín consideraba el carnaval como una agrupación de la cultura popular y la cultura oficial, superando la dualidad natural [Polák 2011:46]. En consecuencia, las voces de la ortodoxia y de la heterodoxia se enfrentan desde el comienzo de la tragicomedia $(\mathrm{I}, 1)$, de mano de los representantes de ambos mundos:

\section{PEDRO GAILO}

[...] Éstos que andan por muchas tierras, torcida gente. La peor ley. Por donde van muestran sus malas artes. [...] ¡A otro lugar era el iros con vuestros malos ejemplos, y no venir con ellos a delante de Dios!

$$
\text { LUCERO }
$$

Dios no mira lo que hacemos. Tiene la cara vuelta.

$$
\text { PEDRO GAILO }
$$

¡Descomulgado!

\section{LUCERO}

¡A mucha honra! ¡Veinte años llevo sin entrar en la iglesia!

¿Te titulas amigo del Diablo?

$$
\text { PEDRO GAILO }
$$$$
\text { LUCERO }
$$

Somos compadres.

$$
\text { PEDRO GAILO }
$$

Ahora ríes enseñando los dientes, ya te llegará el rechinarlos.

\section{LUCERO}

No temo esa hora.

POCA PENA

Hasta las bestias del monte temen. PEDRO GAILO

Para toda conducta hay premio o castigo, enseña la doctrina de Nuestra Santa Madre la Iglesia.

Junto al Sacristán, es también Marica la Reina, su hermana, una de las encargadas de entonar las palabras de la ortodoxia en numerosas ocasiones, refiriéndose a Mari-Gaila, su cuñada: "se pasa la noche por ventorrillos y tabernas, perdiendo la conducta [...] Milagros del vino y mal mirar por la conducta $[. .$.$] A mí me ata la$ decencia" (II, 1). Y junto a ella, el resto de mujeres de la aldea (III, 3): los conceptos del "vivir honradamente", la "fama" y la "decencia" actúan como máximas morales. Son precisamente estas voces colectivas el sistema por el que circula el veneno de la crueldad.

El ideario colectivo suele vincular el concepto de crueldad a los actos de violencia verbal o física; sin embargo, en palabras de Artaud, la crueldad "será sanguinaria cuando convenga, pero no sistemáticamente" [2001:139]. Efectivamente, se trata de un acto de violencia, aunque uno mucho más sutil y extendido del que solemos concebir como tal. Se hace necesario ampliar el concepto para comprender cuán largo es su alcance real, trascendiéndolo del modo en que lo hicieran Nietzsche, Valle-Inclán o, de nuevo, el propio Artaud, autor del "Primer Manifiesto de la crueldad"5 [2001:101-114], así como del "Segundo" [2001:139-146]: "Todo cuanto actúa es una crueldad" - consideraba Artaud, y añadía-, "Sin un elemento de crueldad en la base de todo espectáculo, no es posible el teatro. En nuestro presente estado de degeneración, sólo por la piel puede entrarnos otra vez la metafísica en el espíritu" [2001:112]. La inauténtica sociedad reclama una "mordedura concreta" en el corazón y los sentidos, una convulsión certera; un acercamiento de todos aquellos sueños prohibidos de crimen y erotismo que se ocultan bajo la máscara, y que vendrán a desbordar "en un plano no fingido e ilusorio, sino interior" durante la representación teatral [2001:104]. El origen de esa crueldad ya lo ha intuido el dramaturgo en "todo cuanto actúa", en el mismo vivir, pues el vivir se ejecuta inevitablemente bajo una ordenación a la que él se refiere como "determinismo filosófico", uno que es "desde el punto de vista de nuestra existencia, una imagen de la crueldad" [2001:116].

Ese "determinismo" es el definido por Mèlich [2014] como "lógica moral", a la cual es inherente la crueldad. La lógica moral conlleva una serie de procedimientos: el primero es una ordenación de todos los aspectos de la vida en el marco de una serie de categorías creadas, siendo algunos de ellos susceptibles de una inclusión dentro de sus márgenes, así como otros, necesariamente, de una consecuente exclusión. La lógica es "una forma de vida, una forma de ordenar la vida, un modo-de-ser" [2014:133]. El sometimiento a lo categorial de todos los seres -en calidad de compuestos físicos y psíquicos- y elementos existentes supone la instauración de la oficialidad de la que veníamos hablando, y de una contrapuesta pero complementaria anti-oficialidad. Este marco categorial social, o lógica moral, cruel desde sus mismos cimientos, crea sobre esa oficialidad un "ámbito de inmunidad", y dota a los actos de sus participantes de una legitimidad ciega a la hora de actuar contra los disidentes, los participantes de la anti-oficialidad. La lógica moral, por tanto,

Establece y clasifica a priori quién tiene derechos y quién deberes, quién debe ser tratado como persona y quién no, de quién podemos o debemos compadecernos y frente a quién tenemos que permanecer indiferentes [...] la moral afirma que hay seres que deben ser tomados como modelos por su comportamiento ejemplar y seres que tienen que ser descalificados por atentar a las buenas costumbres [...] no serán objeto de respeto moral, $\mathrm{y}$, entonces, se situarán fuera de la protección de la ley [2014:14].

Esta operación conlleva un procedimiento de clasificación absoluto, un sometimiento de lo singular al marco categorial, del individuo a la moral colectiva, pues, en palabras de Nietzsche, "todo concepto se genera igualando lo no-igual" [2014: 28]. Entra así en juego el siguiente procedimiento de la lógica moral, encargado 
de hacer efectiva su clasificación a través de la "re-organización" de los disidentes de la norma. El individuo forma parte de un todo, se integra en sus cánones o es excluido de ellos; pero el "todo" termina triunfando sobre "lo uno", sobre el ser disímil, porque no está dentro del rango de lo apropiado y aceptado, y porque, por lo tanto, la reorganización debe recaer sobre él como lo hace sobre el resto de individuos, ya convertidos en colectividad. La eliminación de esa disimilitud, legitimada por la lógica moral, tiene dos vías: el sometimiento o normalización, y la aniquilación. "Frente a la disonancia, la coherencia extrema" [2014:34]: ese parece ser el lema de la lógica de la crueldad.

Dentro de este concepto ampliado de crueldad reside, sin duda, esa veta violenta de tipo guiñolesco que tanta curiosidad parece suscitar entre el ser humano: el sadismo y su espectáculo del dolor innecesario, el maltrato, la apatía y falta de compasión ante la desgracia ajena están en Divinas palabras; dentro de la tradición del Grand Guiñol $^{7}$, afiliada a lo grotesco, también el resto moral, el cuerpo comido por los cerdos, y el monstruoso Engendro; el padre despiadado que propone el abandono de su hijo con la frialdad y el humorismo más retorcido (Lucero, I, 1); el padre vengativo y alcoholizado que trata de emprender la violación de su propia hija (Sacristán, II, 6), etc. Sin embargo, la mayoría de estas muestras de crueldad son de tipo colectivo y, física y verbalmente violentas o no, producto de esa crueldad imperante y omnipresente que es la lógica moral. Esta crueldad colectiva se dirige en dos direcciones: hacia uno mismo y, como consecuencia, hacia la alteridad.

La crueldad hacia uno mismo es a la que Nietzsche se refería con la "moral del sufrimiento voluntario". El hombre se encuentra "apresado definitivamente en el hechizo de la sociedad y de la paz", en la que es "prisionero anhelante y desesperado", frustrado por la desvalorización de sus instintos e inhibido, lo que produce que los efectos de esos instintos no expresados hacia una exterioridad recaigan inevitablemente en su interioridad: "la hostilidad, la crueldad, el placer de perseguir, de asaltar, de cambiar, de destruir... todo ello volviéndose contra los portadores de tales instintos: éste es el origen de la mala conciencia" [Aforismo 16, 2007:125-127]. El ser social transforma sus nuevos valores nacidos de la represión -debilidad, impotencia, bajeza y sumisión-en fingidos mérito, bondad, humildad y obediencia, respectivamente, que muestran al exterior y emplean como apaciguador de la propia conciencia. Pero al producirse el encuentro con un estimulante "mundo opuesto y exterior", con la alteridad, se manifiesta un resentimiento que desemboca finalmente en "la rebelión de los esclavos", produciéndose el nacimiento del odio y el deseo de llevar a cabo la venganza imaginada hacia esa realidad esquivada, venganza que una vez ejecutada denominarán "triunfo de la justicia” [Aforismo 10, 2007:77-80].

Este es el tipo de crueldad que vemos entre los habitantes de ese mundo de la oficialidad, de la aldea rural galaica dominada por "la furia escolástica". Son seres inhibidos que luchan por ocultar sus verdaderas pulsiones -particularmente las eróticas- al amparo, o bajo el yugo, de las concepciones de honor y decencia. Sus verdaderos instintos se revelan, sin embargo, de forma inevitable: así ocurre con las pulsiones lujuriosas del Sacristán quien, al modo del Teniente Pascual Astete en Los cuernos de don Friolera, se ve empujado por la presión social a llevar a cabo un acto de venganza contra su mujer adúltera, lo que trata de ejecutar nada menos que a través de la violación de la hija de ambos. La manipulación de las convenciones hace su mella en la conversión del Sacristán en fantoche, reflejo satírico del héroe trágico del auto de fe calderoniano - frívolo, moralizante y anticivilizador, a ojos de Valle-Inclán-. El ser más pusilánime de la tragicomedia se ve forzado a convertirse en figura elevada - para lo que hace falta el apoyo de varias copas de más - por las palabras de su hermana Marica, voz de la ortodoxia (II, 4): “¡Así dejas que la mujer se te vaya extraviada! [...] ¡Ay hermano mío, otro tiempo tan gallo, y ahora te dejas así picar la cresta! ¿Qué te dio esa mala mujer que de tu honra no miras? [...] esa mala mujer, con su conducta, es oprobio de nuestras familias!". Antes que el deshonor, Marica aboga por la venganza y la consecuente "perdición" de su hermano: “¡Tendrás honra!”, exclama ella insistente; “¡La honra de una cárcel!”, replica él. Así las malas lenguas "murmuradoras" obran su papel: la moral colectiva hace recaer sobre el Sacristán el peso del dogma ante el cual no queda más remedio que doblegarse. Ante la desproporcionada reacción del esclavo del código de honor y castigo, Valle-Inclán inicia una de las escenas más lamentables de la obra, en la que el Sacristán, convertido en antihéroe borracho y lascivo, delirante e impotente, deja entre gritos salir las palabras heredadas y repetidas hasta la saciedad:

¡He de vengar mi honra! ¡Me cumple procurar por ella! [...] ¡Ave María; si así no fuera, quedaban por cumplir las Escrituras! [...] Con este cuchillo he de cortar la cabeza de la gran descastada [...] La mujer que se desgarra del marido, ¿qué pide? Y los malos ejemplos, ¿qué piden? ¡Cuchillo! ¡Cuchillo! ¡Cuchillo!

$\mathrm{Su}$ mujer Mari-Gaila, representante de la degradación moral, encarna un conjunto de figuras femeninas míticas tales como la malcasada y la adúltera — palabras ambas que aparecen en boca de Marica del Reino- la

\footnotetext{
Tanto la división en procedimientos de la lógica moral como la aplicación de los conceptos de “organización” y “re-organización” son propuestas personales de una lectura de la obra de Mèlich.

El teatro del Grand Guignol fue sin duda conocido por Valle. Su origen se encuentra en un pequeño salón teatral creado en París en 1896 por Maurice Magnier, y dirigido un año más tarde por Oscar Méténier, bajo el nombre de Grand-Guignol. Su sucesor, Max Maurey, fue el encargado de teñir las representaciones del horror que lo caracterizó. Rápidamente propagado por Europa, llegó a España en 1912 de la mano de la Compañía Italiana del Grand Guignol, y se perpetuó a través de creaciones patrias como la de la Companyia Grand Gruignyol Català de Mantua y Santacana.

8 Estas ideas y citas han sido extraídas de los "Tratados $1^{\circ}$-"“"Bueno y malvado", "bueno y malo"“- y $2^{\circ}$-"“Culpa", "mala conciencia" y similaresde Nietzsche [2003]

9 En términos del propio Valle-Inclán ("Prólogo" a Los cuernos de don Friolera).
} 
femme fatale finisecular de carácter fuerte, rebelde, erótico y vitalista ${ }^{10}$, las antiguas Venus y Ceres, y una versión no arrepentida de la bíblica María Magdalena poseída por los siete demonios ${ }^{11}$ [Ríos Sánchez 2001]. Además del contenido simbólico, Mari-Gaila está dotada de una belleza única en Divinas palabras - tan solo compartida con los espacios naturales - que se corresponde con sus también especiales atributos de "ser humano impermutado por la falsificación de la dignidad humana" [Jerez Farrán 1989:88]. Con ella, Valle-Inclán realiza una apología del "amoralismo estetizante" y de la fuerza en la que algunos encuentran un vínculo evidente con el ideario nietzscheano: se trata de dos vertientes complementarias mitificadas en Apolo y Dionisos con dos últimos patrones como resultado, que Valle-Inclán había encarnado en Bradomín y Montenegro respectivamente, y ahora focaliza, fundidos, en su heroína Mari-Gaila: Belleza y Vida [Sobejano 1967:225]. Tanto ella como el anterior binomio de personajes son "héroes [que] se nos aparecen como dioses condenados a vivir vida de hombres" [Nietzsche en Sobejano 1967:227]. Este haz de tradiciones conjugado en Mari-Gaila se manifiesta en la escena final de Divinas palabras, en la cual la adúltera es descubierta en pleno acto sexual por los aldeanos, subida a la fuerza a un carro y obligada a desnudarse, encarnando así a la Venus desnuda y a la diosa Ceres en su carro tirado por serpientes; en estas circunstancias es llevada hasta la iglesia donde su marido aguarda. Mari-Gaila es un ser disidente de la lógica moral, de la doctrina vinculada a la norma católica que establece el carácter pecaminoso de la lujuria y del adulterio; Mari-Gaila es un ser primitivo, auténtico y espontáneo, su moral, su ley, no es la culturalmente establecida, sino la dictada por la naturaleza - en recuerdo al marqués de Sade-. Mari-Gaila es bella, es armoniosa, su tez es blanca o colorida, sus gestos elegantes, un personaje mirado desde abajo desvinculado de lo mundano y en constante reminiscencia a una superioridad divina. Representa la expresión sexual redimida y pudorosamente escondida por los aldeanos, exhibe su vergüenza y tentación insistentemente coaccionada. Por su naturaleza y por sus instintos, Mari-Gaila - “¡Perra salida! [...] ¡Afrenta de mujeres!" (III, 4)- debe ser neutralizada, el cordero devuelto a su rebaño. La brutalidad de la ignorante reunión de títeres y máscaras movidas ciegamente por el fanatismo lleva a la culpable a través de una implacable violencia física y moral hasta la casa de Dios, donde el juicio deberá hacer de ella lo que el cruel dogmatismo pide para las indignas. Las propias miserias y pecados de los verdugos, la lujuria del Sacristán o de Lucero, al que permiten escapar -"Que se vaya libre. El hombre hace lo suyo propio. En las mujeres está el miramiento" (III, 4)- son colectivamente aceptados. La frustración provocada por la inhibición de la propia depravación interior, nunca expresada, vuelve su ira hacia el propio individuo esclavizado y busca calmar su mala conciencia, malestar que el desorden les produce, a través de la ejecución de la "justicia" obligada. En el movimiento colectivo reside "la secreta inocencia de estos hombres, cuya maldad no parece mostrarse aquí como algo que brote de su individualidad, sino que se basa en leyes ancestrales, en oscuras corrientes subterráneas, en un extravío de su realidad personal" [Pirraglia, 2002: 114].

Esta penúltima escena establece un vínculo evidente con la imagen goyesca de la infamia, recreada en "No hubo remedio", el grabado 24 de la serie de Los caprichos. ${ }^{12}$

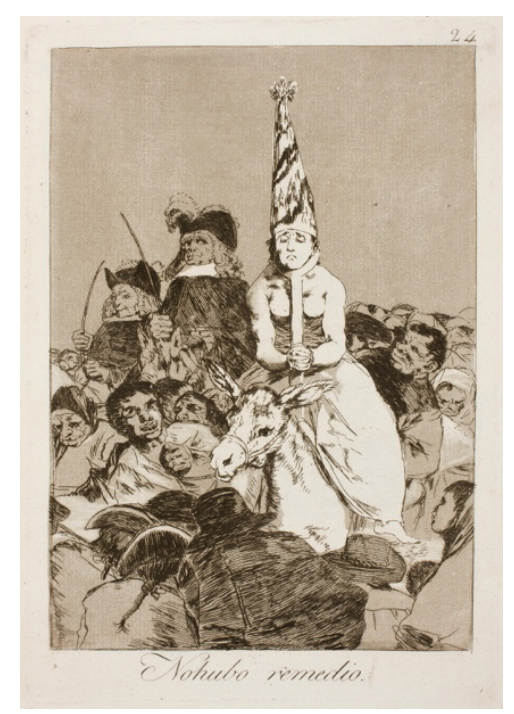

"No hubo remedio", serie Los caprichos, Francisco de Goya

Esta crueldad del sometimiento se torna, a pesar de su brutalidad, crueldad mitigada frente a la ejercida sobre el contrapunto de Mari-Gaila, un ser inocente, desvalido y de aspecto grotesco: Laureano. Señala Cabañas Vacas que son precisamente ambos personajes los núcleos en torno a los cuales se estructuran las dos líneas de acción de la obra: el adulterio de la mujer, la explotación del inválido [1995: 183]. Laureano funciona como filtro de conmoción, prisma del horror y de la crueldad, constituyendo un primer espejo cóncavo sobre el que se refleja la degradación moral más desalmada de la sociedad a través del aspecto deformado del ser humano. Con Laureano muestra Valle-Inclán un distanciamiento mayor que con ninguno de los demás personajes, actitud completamente apática que resulta indispensable para dar a luz al esperpento. El autor se convierte así en un titiritero hábil capaz de concebir un pequeño y deformado humano que personifica al títere, "símbolo eficaz de la pequeñez espiritual del hombre, de la ausencia de au-

\footnotetext{
10 No hay que olvidar la presencia de esta faceta femenina como constante en otras obras de Valle-Inclán, como Sonata de estio (1903) - encarnada por la niña Chloe - o La cabeza del Bautista (1927) — mito de Salomé-. La figura de la femme fatale fue común a gran parte de la literatura internacional finisecular y de principios de siglo, y de reconocida relevancia entre dramaturgos europeos como Oscar Wilde con Salomé, o el alemán Franz Wedekind con su personaje Lulú.

11 Al igual que María Magdalena, otras figuras bíblicas como Lilith o Judith participaron de la tradición de la mujer cruel o femme fatale siendo sus tradiciones recuperadas por la literatura europea.

12 Disponible online a través de la página del Museo del Prado: $<$ https://www.museodelprado.es/goya-en-el-prado/obras/ficha/goya/no-hubo-reme$\underline{\mathrm{dio}} />$
} 
tenticidad" [Cardona y Zahareas 1987:41-49]. Laureano encarna la más inquietante distorsión del ser, la miseria física y moral; su voz, nacida de un pozo de moscas, es un sonido infértil e incapaz de toda comunicación humana; su cuerpo es el del ser macabro, nauseabundo, sucio y hediondo reducido a bulto. Denominado "engendro", "hijo idiota", "enano hidrocéfalo", Laureano ha perdido en sus múltiples denominaciones su condición humana, $\mathrm{y}$ es en este proceso en el que reside la mayor de las crueldades: su valor económico lo acerca al estado cosificado, y lo primitivo de sus capacidades y cualidades al animal, privándole en ambos casos - a ojos de la humanidad- de sus legítimos derechos humanos.

La cosificación es apreciable en el mercantilismo y utilitarismo que este ser despierta en los avariciosos personajes de ambos mundos, oficial y farandulero: Laureano es para casi todos "el carretón", debido a la improvisada cuna donde su madre lo transporta por las ferias para ganar dinero, cuyo destino tras su muerte expresa una de las mujerucas en los siguientes términos: “¿Adónde rodará?” (I, 3); “carretón” es incluso para sus propios familiares, desde las desalmadas Mari-Gaila y Marica que se disputan su custodia por los provechos que supone, hasta su propia prima Simoniña; Laureano es un "horno de pan" (I, 2), un "tesoro" (II, 2), etc. El Juez Pedáneo, que pacta los términos de su custodia, voz de la ortodoxia y el poder, habla de él de un modo animalizado y cosificado:

Si como la finada no deja otro bien que el hijo inocente, dejase un par de vacas, cada cual se llevaría su vaca de la corte. Tal se me alcanza. Y si dejase dos carretones, cada cual el suyo [...] Un suponer: Sois dos llevadores de un molino. De lunes a miércoles saca el uno la maquila, y el otro, de jueves a sábados. Los domingos van alternados (I, 5).

Laureano es niño-molino y niño-vaca, motor de un cruel "mercantilismo práctico" y de la inhumana indiferencia de sus familiares [Esturo Velarde 1986:137]. También es el "desgraciado sin luz de razón" (I, 2), quizá como castigo por su condición de "hijo del pecado" de su madre (II, 1). Laureano es incluso objeto de vejaciones y crueles juegos - transfiguración de los infantiles - en los que participa inocentemente, y durante los cuales le emborrachan: "Págale otra copa y estaos atentos. Cuando tiene dos copas se pone un mundo de divertido. Haz la rana [...] Píntale unos bigotes como los del Cáiser [...] Voy a afeitarle una corona" (II, 7). De Mari Gaila sufre otros abusos como la exposición de su cuerpo desnudo en las ferias, y maltratos como la falta de higiene que le produce heridas. Su muerte es producto del último juego cruel al que es sometido, y de la indiferencia de todos los presentes en el momento en que se produce. Ante la muerte del inocente, sus familiares muestran una gran apatía, y aunque no falta un cumplido planto -parodización y degeneración del género- éste no está motivado sino por la pérdida económica que la muerte de este "horno de panes" supone (II, 7), e incluso por su transformación de ganancia en gasto y estorbo legal (II, 9). Abandonado su cadáver en la noche, el cuerpo frío es alimento para los cerdos ${ }^{13}, y$ después nuevo objeto de ganancias en la recolecta de limosna que se realiza para su entierro expuesto entre camelias en una especie de altar grotesco: rostro desgarrado entre bellas flores, cabeza hidrocéfala convertida en "cabeza de ángel".

La crueldad toma diversos cauces en el caso de Laureano: su vida es tratada con indiferencia y desprecio, y su ser es empleado como medio, nunca como fin en sí mismo. Ambas reacciones se caracterizan en este caso por ser comunes a los mundos de la oficialidad y de la farándula, y por ser producto de una misma crueldad colectiva cuya clave radica una vez más en una categorización: "la moral, al menos la moderna, establece que todo ser humano y todo ser racional posee dignidad [...] al hacer esta afirmación también implícitamente se está proponiendo otra, a saber, que hay "entes", del tipo que sean, que no poseen dignidad", y que por lo tanto son susceptibles de ser utilizados como medios, pues tienen precio y cabe considerarlos dentro del "circuito de lo económico" [Mèlich 2014:148]. El sufrimiento de Laureano, en tanto que ser animalizado y cosificado, está legitimado por su condición inhumana, y por lo tanto indigna: "La 'persona' es la primera categoría que convierte a la lógica de la moral en una lógica de la crueldad", concluye Mèlich. El ser humano-pieza "Stücke", el objeto de recambio "Häftinge", el material humano "Menschenmaterial" son concepciones propias de la lógica moral nazi que poco dejan que desear a "carretón".

Y más allá del aislamiento producido contra el ser indigno animalizado y cosificado, Laureano experimenta un último pero definitivo golpe de crueldad al encarnar la radical heterogeneidad de lo monstruoso - "el extraño, el intruso", en términos de Mèlich-, incapaz de formar parte de ningún espacio posible. El mundo oficial se resiste a su naturaleza, pero incluso el farandulero deviene incapaz de albergar su monstruosidad; el mismo reino animal lo excluye cuando incluso Coimbra, el perro de Lucero, percibe su extraño halo y se aleja. Quizás sea tan solo el reino infernal el capaz de acoger en su seno a seres como Laureano, únicamente contestado en sus propios términos por un "sapo anónimo que canta en la noche" (I, 5): "EL IDIOTA: ¡Hou! ¡Hou! / EL SAPO: ¡Cro! ¡Cro!”. Lo monstruoso es, a diferencia de la mujer amoral, "lo desordenado que no puede ser sometido a un orden" [2014:205], ser esencialmente incapaz de una redención que le permita ser adentrado en el rango de lo normal, al que sólo espera un posible fin: la aniquilación. 


\section{Bibliografía}

Aszyk, Úrsula (1995): "Valle-Inclán - Witkiewicz - Artaud: La teoría del esperpento a la luz de las teorías del teatro puro y del teatro de la crueldad”, Valle-Inclán y su obra. Actas del Primer Congreso Internacional sobre Valle-Inclán, ed. Manuel Aznar Soler y Juan Rodríguez, Barcelona, Universidad Autónoma de Barcelona: 137-147.

Cabañas Vacas, Pilar. (1995): "Valle-Inclán y la tragicomedia”, Quaderns de Filología 1, 1: 173-190.

— (1991): “Teoría de los géneros dramáticos en Ramón del Valle-Inclán”, Ínsula, 531: 16-17.

Cardona, Rodolfo y Zahareas, Anthony N. (1987): Visión del esperpento: teoría y práctica en los esperpentos de Valle-Inclán, Madrid, Castalia, D.L.

Cirlot, Juan-Eduardo (1991): Diccionario de símbolos, Barcelona, Labor.

Crispin, John (1988): "La batalla maniquea irónica en Divinas palabras", Ramón del Valle-Inclán, coord. Ricardo Doménech, Madrid, Taurus: 189-201.

Ena Bordonada, Ángela (2006): Valle-Inclán y la religión, Madrid, Ediciones del Orto.

Esturo Verlarde, Juan Carlos (1986): La crueldad y el horror en el teatro de Valle-Inclán, Sada, Edicións do Castro.

Iglesias Feijoo, L (1991): “El concepto de tragicomedia en Valle-Inclán”, Ínsula, 531: 18-22.

Jerez Farrán, Carlo (1989): El expresionismo en Valle-Inclán: una reinterpretación de su visión esperpéntica, A Coruña, Ediciós Do Castro.

Kayser, Wolfgang (1963): The Grotesque in art and literature, Bloomington, Indiana University Press.

Mèlich, Joan-Carles (2014): Lógica de la crueldad, Barcelona, Herder Editorial.

Nietzsche, Frederick (2007): La genealogía de la moral, Madrid, Tecnos.

Pavis, Patrice (1984): Diccionario del teatro. Dramaturgia, estética, semiología, Barcelona, Paidós.

Perdono, Unvelina (1995): "El Grand guignol y el Retablo de la Avaricia, la lujuria y la muerte", Valle-Inclán y su obra. Actas del Primer Congreso Internacional sobre Valle-Inclán, ed. Manuel Aznar Soler y Juan Rodríguez, Barcelona, Universidad Autónoma de Barcelona: 609-615.

Pirraglia, Elvira (2002): Valle-Inclán y su macrotexto literario, Montevideo, Trilce.

Polák, Petr (2011): El esperpento valleinclaniano en el contexto del arte grotesco europeo, Brno, Masarykova Univerzita. Recurso web http://hdl.handle.net/11222.digilib/124525, Fecha de consulta: 3-XI-2019.

Ríos Sánchez, Patrocinio (2001): "Valle-Inclán: mistificación de textos bíblicos en Divinas Palabras", Revista de literatura, vol. 63, 125: 157-183.

Sobejano, Gonzalo (1967): Nietzsche en España, Madrid, Gredos.

Umpierre, Gustavo (1971): Divinas palabras: alusión y alegoría, Chapel Hill Department of Romance Languages, University of North Carolina, D. L.

Valle-Inclán, Ramón María (2011): Divinas palabras, Madrid, Austral. 